\title{
Artigo
}

\section{O fim do superciclo das commodities internacionais e seus reflexos na economia brasileira}

The end of the international commodity supercycle and its effects on the brazilian economy

DOI: 10.5752/P.1809-6182.2016v13.n1.p36

Rafael Henrique Dias Manzi ${ }^{1}$

Recebido em: 02 de fevereiro de 2016 Aprovado em: 24 de maio de 2016

\section{Resumo}

O principal objetivo do trabalho é examinar os efeitos do fim do ciclo das commodities internacionais sobre a formação da atual crise da economia brasileira.

Palavras-chaves: Economia brasileira. Commodities internacionais. Crise econômica.

\section{Abstract}

The main objective of the paper is to examine the effects of the end of the cycle of international commodities on the formation of the Brazilian economic crisis.

Key-words: Brazilian economy. International commodities . Economic crisis. 
$\mathrm{N}$ o início do século 21, dezenas de países - que outrora eram chamados de "em desenvolvimento", "terceiro mundo" e hoje chamados emergentes - que ocupavam lugar secundário dentro da economia internacional passaram a registrar elevadas taxas de crescimento econômico. A aceleração do crescimento econômico no mundo emergente - especialmente China e Índia - teve reflexos diretos para os países que tradicionalmente são exportadores de matérias primas e commodities internacionais.

Com a aceleração do processo de urbanização e da própria renda nos dois países mais populosos ${ }^{2}$ do mundo houve um crescimento natural da demanda por commodities internacionais ao longo da década de 2000. Esse fenômeno é o principal fator que explica o crescimento dos preços e do consumo de matérias primas em nível mundial nas duas últimas décadas. Embora esse fenômeno seja perceptível na Índia, o principal responsável pelo surgimento do atual "superciclo" ou boom das commodities internacionais é o elevado consumo chinês nas duas últimas décadas que está chegando ao fim com a desaceleração econômica do país (SHARMA, 2013).

$\mathrm{O}$ apetite da China por commodities internacionais pode ser observado por meio aumento da demanda e consumo interno dos chineses de commodities internacionais. Em 2015, por exemplo, a China consumiu aproximadamente $54 \%$ da produção global de alumínio, 50\% de níquel e 46\% da produção global de zinco. No tocante às commodities agrícolas, apesar do consumo ser menor (algodão $31 \%$, arroz $30 \%$ e milho $22 \%$ ) os valores continuam bastante significativos e com impactos positivos para os países exportadores de commodities internacionais. (WORLD ECONOMIC FORUM, 2015).

2. Segundo dados das Nações Unidas de 2015 a população da China é de aproximadamente 1.376 bilhôes de pessoas e a da Índia 1.311 bilhóes. Os dois países possuem ao redor de $36,5 \%$ da população global que é estimada em 7.439 bilhões de pessoas.
A magnitude desses valores pode ser igualmente percebida quando são observadas as pautas de importação da China e da Índia. No caso chinês, as importaçóes de produtos e bens básicos saltaram de US\$ 31 bilhões em 2001, para US\$ 297 bilhôes em 2008 e US\$ 525 bilhóes em 2014. Na Índia, as importaçóes desses bens cresceram no mesmo período de US\$ 20 bilhóes para US\$ 118 bilhóes, e posteriormente para US\$ 195 bilhóes. Ou seja, nos dois países mais populosos do mundo houve um crescimento sem precedentes da demanda por commodities internacionais. As compras chinesas se multiplicaram em aproximadamente dezessete vezes e as indianas em dez vezes em um período inferior a duas décadas (2001 - 2014). (Banco Mundial, 2015).

Com a elevação da demanda externa, os preços das commodities internacionais, que estavam em baixa ao longo da década de 1990, registraram substancial aumento como pode ser observado no Gráfico 1. O preço do petróleo saltou de valores próximos a 25 US\$ dólares o barril no início de 2000 para aproximadamente US\$130 em junho de 2008. Com o início da crise global de 2008 os preços sofreram uma brusca queda, mas voltaram a crescer e atingir a marca dos US\$ 100 já em 2011. Os contratos de tonelada da soja por metro cúbico eram negociados em US\$ 184 dólares no início de 2003 na China. Esses valores foram reajustados ao longo da década e ultrapassaram os US\$ 300 dólares em 2007. No pós-crise de 2008, o preço chegou a US\$ 500 ao longo de 2012 e reduziu-se a partir do fim de 2015, quando os preços retornaram aos valores de 2007. No tocante aos minérios de ferro, uma das principais commodities internacionais importadas pela China houve um crescimento considerável dos preços ao longo da década de 2000 . O custo de importação da China da tonelada métrica de minério de ferro, que era de aproximadamente US\$ 13 ao longo de 2003, elevou-se para valores superiores à US\$ 100 no início de 2010. (INTERNATIONAL 
Figura 1. Evolução anual dos preços das commodities internacionais por grupos. $2005=100 \cdot(2003-$ dez/2015)

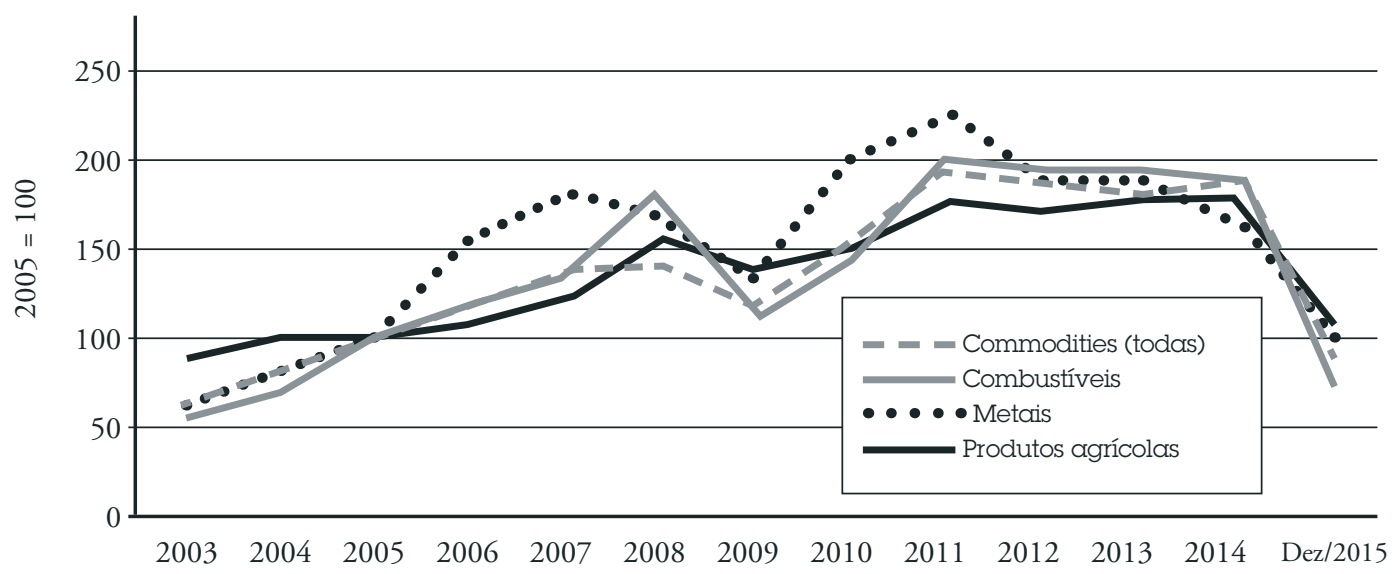

Fonte: Elaborado pelo autor com dados do International Monetary Fund (2016)

MONETARY FUND, 2016). Quando se observa a evolução das commodities internacionais por grupos, é possível ver a magnitude do crescimento dos preços do início da década de 2000 até 2014.

A partir de 2013, os rumores acerca de uma forte desaceleração econômica (hard landing) nas principais locomotivas do Sul contaminaram o humor dos mercados financeiros internacionais centrais. Mais uma vez, a principal fonte de preocupação advinha da China em virtude da importância do país para a performance da economia mundial. As preocupaçóes com a China têm como origem os desequilíbrios econômicos do país que podem, já no curto prazo, comprometer suas taxas de crescimento econômico ${ }^{3}$. Assim, com a redução do crescimento econômico da China para patamares ao redor de $6-7 \%$, ou ainda menor na visão de alguns analistas, os mercados internacionais previram uma redução da demanda chinesa por commodities internacionais com efeitos negativos sobre os preços desses produtos (BALBONES, 2016; IMF, 2015).

Como demonstra o Gráfico 1, a partir de 2014 os preços das commodities sofreram elevadas perdas nos mercados internacionais. Nos três grupos de commodities (combustíveis, metais e

3. Sobre as causas de curto prazo da desaceleração econômica e as origens dos desequilíbrios econômicos na China ver Lynch (2016), Balbones (2015) e Roach (2015). produtos agrícolas) houve forte redução nos preços internacionais. No caso dos combustíveis, a redução dos preços internacionais do petróleo e outros hidrocarbonetos estão ligados mais ao aumento da oferta do que propriamente a desaceleração da economia chinesa e global ${ }^{4}$.

A redução do preço das commodities internacionais e da demanda externa têm sido apontadas como importantes causas na formação da crise econômica brasileira iniciada ao longo de 2015. No decorrer das duas últimas décadas, a pauta das exportaçóes brasileiras sofreu importantes alteraçóes em virtude do processo de "primarização" portações nacionais e do crescimento da importância relativa de commodities internacionais na vendas externas do país. De fato, a importância das exportaçóes de bens básicos e agrícolas é percebida quando

4. Um fator fundamental para a redução no preço do petróleo foi a maturaçáo de investimentos que foram feitos ao longo da década de 2000, o aumento da produçấo do óleo de xisto nos Estados Unidos e o aumento da competitividade das energias renováveis - eólica e solar. Além disso, o maior exportador de petróleo mundial, Arábia Saudita, alterou sua política de manutençáo dos preços internacionais e náo reduziu sua produção de petróleo quando os preços começaram a cair nos mercados internacionais. Sobre o petróleo e a política da Arábia Saudita ver Viola e Basso (2015).

5. Primarização das exportaçôes é um termo utilizado para explicar o fenômeno do crescimento da participação das exportaçôes de bens básicos e primários de um país. Assim, ocorre uma redução da exportação de bens industrializados, por exemplo. 
se observa a pauta de exportação do país nas duas últimas décadas. Em 2001, os produtos básicos e agrícolas representaram aproximadamente $26 \%$ das exportaçóes brasileiras. Ao longo dos anos 2000, as exportaçôes de bens básicos e produtos agrícolas ganharam participação nas vendas externas do Brasil e representaram em 2010, $44 \%$ das exportaçóes totais e 46\% em 2014. (BRASIL, 2016).

Nesse contexto, as exportaçóes brasileiras atingiram seu pico em 2011, quando o total vendido pelo país no exterior alcançou US\$256 bilhôes. Somente as exportaçôes que incluem todos os produtos básicos e bens básicos alcançaram US\$ 122 bilhōes. As vendas externas do grupo de bens composto pelos minérios metalúrgicos (ferro, cobre e alumínio) representaram aproximadamente $17,2 \%$ do total exportado pelo país ou US\$ 44 bilhóes em 2011. As exportaçôes oriundas da soja e derivados totalizaram US\$ 23 bilhōes e representaram 9,8\% no total das vendas externas. No terceiro grupo de commodities mais importante da pauta de exportação brasileira, formado por carnes e derivados, as exportaçóes somaram US\$15,3 bilhões (BRASIL, 2016).

A magnitude da queda dos preços internacionais e da própria demanda pode ser observada quando são analisadas as exportaçóes brasileiras desses mesmos produtos em 2014 e 2015. No tocante as exportaçóes de soja, as vendas externas apresentaram um declínio de 10\%, entre 2014 e 2015 , e o preço da tonelada teve uma redução média de 24\% (US\$ 509 dólares em 2014 para US\$ 386 em 2015). Mas nada se compara à queda de receitas oriunda dos minerais metalúrgicos. As exportações totais que em 2014, somaram US\$ 25 bilhôes foram reduzidas para US\$ 14 bilhōes em 2015, com o preço médio se reduzindo, entre 2014 e 2015 , em mais de $48 \%$. No grupo que inclui todos os produtos básicos e produtos agrícolas, as exportações diminuíram de US\$ 109 bilhóes em 2014, para US\$ 87 bilhōes em 2015, o que re- presentou uma queda de aproximadamente $20 \%$. Quando esses dados são comparados com o pico de 2011, as reduçôes das exportaçóes de bens básicos e produtos agrícolas apresentam redução superior a 40\% (BRASIL, 2016).

Não restam dúvidas que a magnitude dos números apresentados sugerem que o fim do superciclo das commodities internacionais tem impacto direto sobre a performance da economia brasileira e dos demais países exportadores. Entretanto, a questão principal é dimensionar o real impacto desse processo sobre o início da recessão da economia brasileira. Apesar dos impactos significativos que as reduções das exportaçôes têm sobre os níveis de atividade econômica do Brasil, entendemos que esse processo é secundário para entender a atual crise econômica no país em virtude de dois aspectos.

Primeiro, como observou Guimarães (2015) é preciso verificar as exportaçóes líquidas ${ }^{6}$ de commodities em detrimento apenas das exportaçóes totais. O autor destaca que "como proporção do Produto Interno Bruto (PIB), as exportaçóes líquidas de commodities do Brasil são muito pouco significativas. Nessa base de dados, correspondem a 4\% do nosso produto." (GUIMARÁES, 2015). Isso porque, apesar de importante exportador de commodities internacionais, o Brasil importa igualmente commodities de outros países. Esses dados sáo confirmados quando confrontamos a pauta das importaçóes brasileiras de produtos básicos e agrícolas entre 2014 e 2015. As importações totais de bens e produtos básicos foram de US\$31,5 bilhóes em 2014 e US $\$ 19,8$ bilhóes em 2015, o que representou uma redução de 37\% na comparação entre os dois anos.

Esses dados são confirmados pelo relatório anual da Comissão Econômica para a América Latina e o Caribe (CEPAL) ao apontar que a queda dos

6. As exportaçóes líquidas são resultado da diferença entre as exportaçôes e importaçóes de um país. 
valores das exportaçốes totais do Brasil foi responsável por uma redução de $16,1 \%$ das exportaçôes nacionais, entre 2014 e 2015, enquanto a redução dos preços dos bens importados foi de aproximadamente $10,9 \%$. Ou seja, apesar da redução dos preços internacionais das exportações brasileiras, os termos de troca do país náo tiveram uma deterioraçâo significativa em virtude igualmente da redução dos preços das importaçôes. Assim, o impacto do fim do super ciclo das commodities internacionais é distinto em cada país em virtude dos níveis de dependência de cada país para na exportação de commodities internacionais serem distintos. Entre 2014 e 2015, as exportações totais foram reduzidas em 16,1\% no Brasil, 16,9\% na Argentina, 29,6\% na Bolívia, 29,2\% na Colômbia, 16,8\% no Chile, $24,5 \%$ no Equador, $16,3 \%$ no Peru, $13,9 \%$ no Paraguai $11,5 \%$ do Uruguai, $40,6 \%$ na Venezuela. Dessa forma, apesar das perdas oriundas consideráveis do Brasil, o país é uma das economias menos vulneráveis aos choques externos de demanda e preços na América do Sul (ORGANIZAÇĀO DAS NAÇÕES UNIDAS, 2015).

Além disso, os países da América do Sul apresentam níveis distintos de dependência de exportaçôes de commodities internacionais. Como demonstra a Tabela 1, Bolívia, Paraguai, Venezuela e Chile apresentam elevado grau de dependência de exportações de commodities internacionais em virtude do elevado percentual que elas representam na renda nacional. Ao mesmo tempo, o Brasil é o país da região em que a menor parte da renda nacional depende de exportaçóes, o que em tese diminui os impactos adversos do fim do super ciclo das commodities sobre o PIB nacional. Ao serem comparados os índices de dependência de commodities internacionais na renda nacional (participação das exportaçóes nacionais de commodities no PIB) e o desempenho econômico dos países ao longo de 2014, 2015 e 2016, fica nítido que outros fatores além das commodities estão influenciando o desempenho econômico dos países da região (UNITED NATIONS CONFERENCE ON TRADE AND DEVELOPMENT, 2014). Dos três países com pior desempenho econômico na região, somente a Venezuela apresenta elevada dependência de exportaçôes de commodities internacionais na renda nacional (20.2\% do PIB). Como observou Werner (2016),

The regional recession, however, masks the fact that most countries continue to grow modestly but surely. In particular, country specific developments are being determined by the interplay between external shocks and domestic fundamentals. While countries with strong policy frameworks have been adjusting to external shocks smoothly, countries with weaker domestic fundamentals are experiencing significant downturns. The sizeable decline in commodity prices (about 30 to 50 percent relative to its peak depending on the country) has led to significant losses in export revenues (estimated at around $\$ 200$ billion for the 7 listed economies $\left.{ }^{7}\right)$. However, the sizes of the terms of trade shocks relative to the sizes of these economies (less than 1 percent of GDP for Argentina, Brazil, and Mexico in 2015 and 2016) are not enough to explain the severity of contraction in some cases. Indeed, our negative growth projection is driven by four countries (Argentina, Brazil, Ecuador, and Venezuela), as the decline in commodity prices in combination with macroeconomic imbalances and microeconomic distortions has led to sharp declines in private investment

Segundo, a crise econômica brasileira teve início antes do fim do super ciclo das commodities internacionais. O Comitê de Dataçáo de Ciclos Econômicos $(\mathrm{CODACE})^{8}$ publicado pela Fundação Getúlio Vargas (FGV) observou que a economia brasileira entrou em recessão econômica a partir do segundo trimestre

7. Argentina, Brasil, Chile, Colômbia, México, Peru e Venezuela.

8. O CODACE é um comitê criado pela FGV em 2008 com o objetivo de determinar os ciclos econômicos brasileiros. Sobre o CODACE ver: Fundaçấo Getúlio Vargas (2015). 
Tabela 1- Participação das exportações de commodities internacionais em \% do PIB em 2012/2013 e tơxars de crescimento econômico em 2014, 2015 e 2016. (\% do PIB)

\begin{tabular}{c|c|c|c|c}
\hline País & $2012 / 2013$. & 2014 & 2015 & 2016 \\
\hline Argentina & 10.8 & 0.4 & 1.5 & -1.0 \\
\hline Bolívia & 40.5 & 5.4 & 4.1 & 3.5 \\
\hline Brasil & 6.8 & 0.1 & -3.8 & -3.5 \\
\hline Chile & 24.7 & 1.8 & 2.1 & 2.1 \\
\hline Colômbia & 13.2 & 4.5 & 3.0 & 2.7 \\
\hline Equador & 25 & 3.8 & -0.6 & 0.0 \\
\hline Paraguai & 26.6 & 4.3 & 3.0 & 3.8 \\
\hline Peru & 18.6 & 2.3 & 2.7 & 3.3 \\
\hline Uruguai & 12.8 & 3.4 & 2.5 & 2.2 \\
\hline Venezuela & 20.2 & -4 & -10.0 & -8.0 \\
\hline
\end{tabular}

Fonte: Elaborada pelo autor com dados extraídos da UNCTAD (2014) e IMF (2015). Os anos de 2015 e 2016 sáo baseados em estimativas do próprio FMI.

Figura 2. Evolução trimestral da FBCF e do PIB entre 2011 e 2015 (taxa acumulada ao longo do ano)

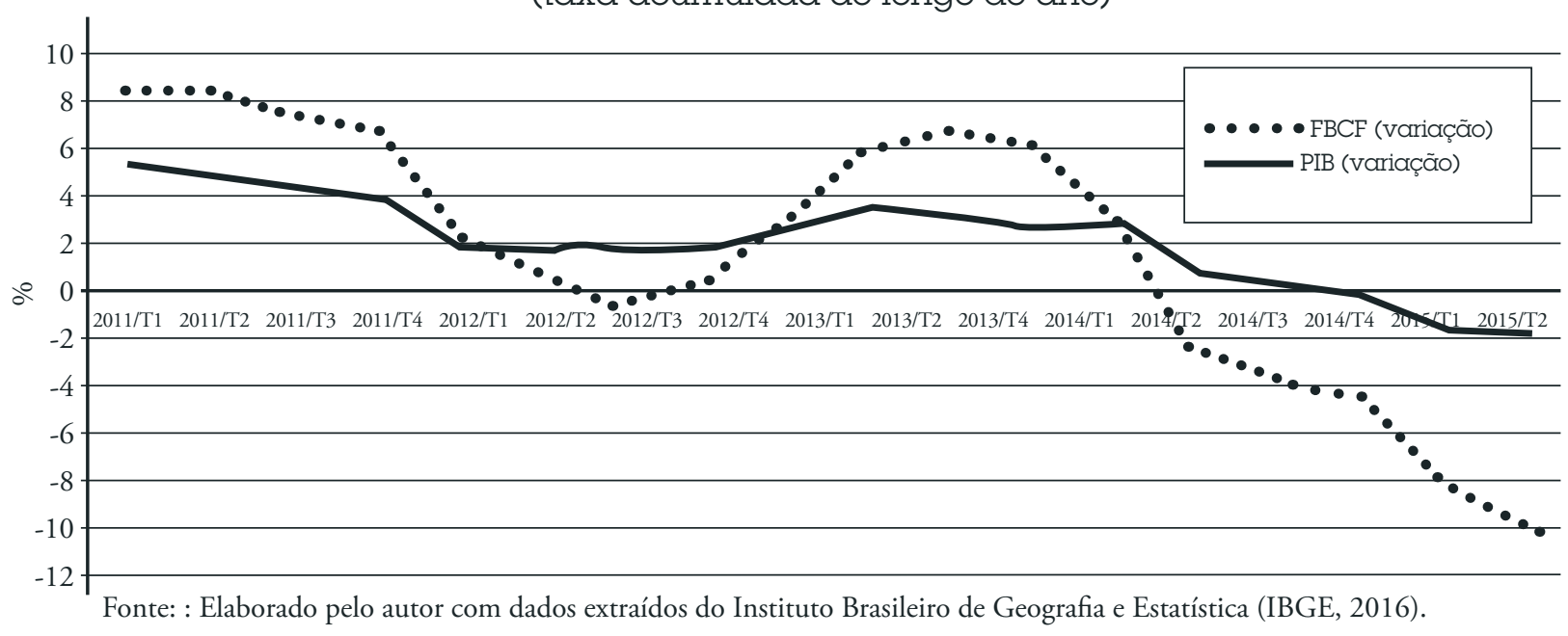

de 2014. Apesar da taxa de crescimento econômico do PIB ter sido de $0,1 \%$ em 2014 (o que significa uma reduçáo da renda per capita em virtude do crescimento demográfico da população), a recessão econômica teve início ainda no início de 2014.

No mesmo contexto, o monitor do PIB - relatório da FGV - aponta que o PIB acumulado em 12 meses tornou-se negativo a partir de dezembro de 2014, sendo a queda do investimento o principal responsável pelo início da recessão econômica. Relatório do Centro de Estudos do Instituto Brasileiro de Mercado de Capitais (IBMEC) INSTITUTO BRASILEIRO DE MERCADO DE CAPI-
TAIS (CEMEC) de outubro de 2015 aponta que, entre 1997 e 2015, existe forte correlação entre o investimento fixo e o crescimento do PIB do Brasil, "a variação do investimento fixo "explica" mais de 80\% da variaçáo do PIB" (CEMEC, 2015, p. 5). A evolução da Formação Bruta de Capital Fixo (FBCF) e do PIB, ambos trimestrais, pode ser observado no Gráfico 2.

O relatório do CEMEC realizou ao longo de 2015 uma pesquisa com 761 empresas não-financeiras ${ }^{9}$ sobre as decisóes de investimento das com-

9. A amostra é composta de 320 empresas não-financeiras de capital aberto e 441 das maiores empresas brasileiras que não possuem capital aberto. 
panhias com o intuito de examinar os fatores que explicam a redução nas taxas de investimento das empresas. Em comparação ao ano de 2010, a taxa de investimento dessas empresas foi reduzida de 8,6\% do PIB, para 4,7\% em 2014. Esses resultados apenas confirmam os dados disponibilizados pelo IBGE acerca da taxa de investimento na economia brasileira e reforçam o caráter interno da recessão brasileira. De acordo com IBMEC (2015, p. 5),

Certamente a reversão da tendência de crescimento dos preços de commodities, origem dos ganhos de relações de troca auferidos no período anterior, bem como a moderação do impacto do crédito ao consumo imposta pelo elevado endividamento das famílias tem gerado impactos negativos sobre o crescimento. Entretanto, existem razóes para acreditar que o principal fator de arrefecimento da economia e sua entrada em recessão resulta da forte queda dos investimentos, seja por seu efeito direto sobre a demanda seja pelo seu efeito multiplicador de renda, além de elevar o crescimento potencial da economia.

Nas eleições presidenciais de 2014, o acirramento das disputas eleitorais levou a um intenso debate entre governistas e oposicionistas acerca da redução das taxas de crescimento econômico que era já registrada ao longo do primeiro governo de Dilma. Com o início do segundo mandato da presidente Dilma e o aprofundamento da recessão econômica o debate acerca das causas das turbulências na economia brasileira ganhou novo ímpeto em virtude principalmente da desaceleração econômica de importantes economias emergentes ao logo de 2015. Apesar do fim do superciclo commodities afetar importantes cadeias do setor produtivo brasileiro - especialmente petróleo, agronegócio e mineração -, as causas para a recessão econômica tem origens em desequilíbrios internos da economia brasileira quando são observados os indicadores econômicos do país.

\section{Referências}

BALBONES, Salvatore. How weak is China? The real story behind the economic indicators. Foreign Affairs, Jan. 2016. Disponível em: <https://www.foreignaffairs.com/articles/china/2016-01-31/how-weak-china $\geq$. Acesso em: 31 jan. 2016.

BALBONES, Salvatore. China hits the wall: the Yuan devaluation and the end of the economic miracle. Foreign Affairs, Aug. 2015. Disponível em: <https://www.foreignaffairs.com/articles/ china/2015-08-16/china-hits-wall>. Acesso: 09 dez. 2015.

BANCO MUNDIAL. World Development Indicators. Disponível em: http://databank.worldbank.org/data/reports. aspx?source=2\&Topic=21 Acesso: 25 jan. 2016

BRASIL. Ministério da Indústria e Comércio Exterior e Serviços. Estatísticas de comércio exterior. Brasília: MDIC, 2016. Disponível em: <http://www.mdic.gov.br//sitio/interna/index. php?area $=5>$. Colocar o último link visitado.

FUNDAÇÃO GETÚLIO VARGAS. Monitor do PIB - FGV. São Paulo: FGV, 2016. Disponível em: <http://portalibre.fgv. br/>. Acesso: 15 dez. 2015. Colocar o último link visitado

FUNDAÇÃO GETÚLIO VARGAS. Comunicado CODACE. [S.1.]: FGV IBRE, 04 ago. 2015. Disponível em: < http:// portalibre.fgv.br/main.jsp?lumPageId $=4028808126 \mathrm{~B} 9 \mathrm{BC}$ 4C0126BEA1779E6CAA\&lumItemId=8A7C82C54DB5CA9F014EF87DD67A0B54>. Acesso: 15 dez. 2015.

GUIMARÃES, Bernardo. O quão importantes são as commodities para o Brasil? Folha de Sáo Paulo, 10 nov. 2015. Disponível em: <http://aeconomianoseculo21.blogfolha.uol. com.br/2015/11/10/quao-importantes-sao-as-commodities-para-o-brasil $/ \geq$. Acesso em: 25 nov. 2015.

INTERNATIONAL MONETARY FUND. IMF Primary commodity prices. [S.I.]: IMF, 2016. Disponível em: <http:// www.imf.org/external/np/res/commod/index.aspx>. Acesso em: 25 jan. 2016.

World Economic Outlook Database. Disponível em: https://www.imf.org/external/pubs/ft/weo/2016/01/weodata/index.aspx Acesso: 25 jan. 2016.

INSTITUTO BRASILEIRO DE GEOGRAFIA E ESTATÍSTICA. Contas nacionais trimestrais. [S.1.]: IBGE, 2016. Disponível em: <http://www.ibge.gov.br/home/estatistica/indicadores/pib/defaulttabelas.shtm>. Acesso: 20 jan. 2016.

INSTITUTO BRASILEIRO DE MERCADO DE CAPITAIS. Nota CEMEC 08/15: investimento e recessão na economia brasileira 2010 - 2015. [S.1.]: CEMEC, 2015.

LYNCH, Daniel. The end of China's rise: still powerful but less potent. Foreign Affairs, Jan. 2016. Disponível em: <https:// www.foreignaffairs.com/articles/china/2016-01-11/end-chinas-rise>. Acesso: 15 jan. 2016.

ORGANIZAÇÃO DAS NAÇŌES UNIDAS. Panorama de la insercíon internacional da América Latina y el Caribe. Santiago: CEPAL, 2015. 
ROACH, Stephen S. China's complexity problem. Project Syndicate, Aug. 2015. Disponível em: <http://www.project-syndicate.org/commentary/china-complexity-problem-by-stephen-s--roach-2015-08>. Acesso em: 05 dez. 2015.

SHARMA, Ruchir. Breakout nations. New York: W. W. Norton \& Company, 2013.

UNITED NATIONS CONFERENCE ON TRADE AND DEVELOPMENT. State of commodity dependence. Geneva: United Nations, 2014.

UNITED NATIONS. World population prospects: the 2015 revision: key findings and advance tables. New York: United Nations, 2015.

VIOLA, Eduardo; BASSO, Larissa. Brazilian energy-climate policy and politics towards low carbon development. Global Society, v. 29, n. 3, online, 2015. Disponível em: <http:// www.tandfonline.com/doi/abs/10.1080/13600826.2015.102 8904>. Acesso: 25 nov. 2015.

WERNER, Alejandro. Latin America and the Caribbean in 2016: adjusting to a harsher reality. [S.I.]: IMF direct, Jan. 2016. Disponível em: < http://blogimfdirect.imf. org/2016/01/22/latin-america-and-the-caribbean-in-2016-adjusting-to-a-harsher-reality/>. Acesso: 25 jan. 2016.

WORLD ECONOMIC FORUM. 6 charts that explain China in the global economy. [S.1.]: Weforum, 2015. Disponível em: <http://www.weforum.org/agenda/2015/09/six-charts-that-explainchinaintheglobaleconomy/?utm_content=buffer3a1e5\&utm_medium=social\&utm_source=facebook. com\&utm_campaign=buffer>. Acesso: 10 jan. 2016. 